\title{
Dakwah Komunitas (Sinergitas Masjid Nurul Islam Kalijudan Dan Komunitas Bikers Muslim Dalam Membendung Kristenisasi)
}

\author{
Asmar Ahmad ${ }^{1 *}$ \\ ${ }^{1}$ Program Studi Manajamen Dakwah STIDKI Ar Rahmah, \\ email: asmarabmadalbugiay@gmail.com
}

\begin{abstract}
ABSTRAK
Masjid adalah pusat peradaban dan sentral bagi orang islam didalam kehidupan beragama. Berbagai upaya yang dilakukan musuh-musuh islam dalam melemahkan kaum muslim dari berbagai aspek, maka perlu adanya wadah tertentu untuk meluaskan dakwah para ulama, khususnya di indonesia untuk selalu membentengi iman saudara muslim kita di manapun berada menyatukan umat dan saling tolong menolong untuk kesejahteraan bersama. Salah satu yang harus diperhatikan oleh keislaman kepada Allah ta'ala. Satu-satunya masjid di kota Surabaya yang bergerak di bidang dakwah berbasis komunitas adalah masjid Nurul Islam Kalijudan Surabaya. Tujuan dari penelitian ini adalah untuk mendeskripsikan tentang sinergitas dakwah masjid dan komunitas yang dilakukan di daerah kristenisasi di lamongan. Dalam penelitian ini menggunakan metode kualitatif dengan pendekatan metode kualitatif deskriptif. Dalam sinergitas dakwah, masjid Nurul Islam Kalijudan dan komunitas bikers muslim memperluas jangkauan dakwahnya untuk memberikan kepedulian kepada saudara muslim tertindas dan meperkuat ukhuwah islamiyah. Berbagai upaya yang dilakukan untuk mempertahankan iman saudara muslim kita di daerah kristenisasi dengan tujuan islam rabmatan lil 'alamin.
\end{abstract}

Kata Kunci: Kerjasama dakwah, komunitas, kristenisasi.

\section{ABSTRAK}

Mosques are the center of civilization and central to Muslims in their religious life. The various efforts made by the enemies of Islam in weakening the Muslims from various aspects, it is necessary to have a certain forum to expand the preaching of the scholars, especially in Indonesia to always fortify the faith of our Muslim brothers wherever they are to unite the people and help each other for common prosperity. One thing that must be considered by Islam is to Allah Ta'ala. The only mosque in the city of Surabaya that is engaged in community-based da'wah is the Nurul 
Islam Kalijudan Mosque in Surabaya. The purpose of this study is to describe the synergy of mosque and community preaching carried out in Christianized areas in Lamongan. In this study using a qualitative method with a descriptive qualitative method approach. In the synergy of da'wah, the Kalijudan Nurul Islam Mosque and the Muslim bikers community are expanding the reach of their da'wah to give concern to oppressed Muslim brothers and strengthen Islamic brotherhood. Various efforts have been made to defend the faith of our Muslim brothers in Christianized areas with the aim of Islam rahmatan lil 'alamin.

Keywords: Da'wah cooperation, community, Christianization

\section{PENDAHULUAN}

Sebagai negara yang paling besar penduduknya dari segi keislaman, Indonesia memiliki jumlah penduduk muslim yang soroti dunia dengan keislamannya. Maka patut kita syukuri dengan saling merangkul dan bergandengan tangan untuk memperkokoh ukhuwah islamiyah sesama kaum muslimin. Pada beberapa tahun yang lalu, negara kita banyak di uji oleh becana dengan berbagai ujian bencana alam dan lain sebagainya. Dari situlah kemudian musuh Islam memanfaatkan kesempatan untuk melemahkan kaum muslimin di belahan nusantara yang tertimpa musibah untuk melakukan pergerakan kemanusiaan untuk membujuk orang Islam yang lemah secara ekonomi dan keimanan yang dikikis untuk menukar keyakinnya dengan sembako bantuan dan berbagai fasilitas untuk menekan masyarakat yang lemah untuk murtad dari Islam. Sampai saat ini, banyak daerah kristenisasi yang perlu ditangani oleh instansi dakwah tertentu untuk melakukan pembinaan dalam mempertahankan keislamannya.

Gerakan dakwah masjid berbasis komunitas yang dilakukan bertujuan untuk menyalamatkan keimanan saudara muslim kita yang tertekan dengan iming-iming bantuan sembako serta bantuan yang lainnya untuk memurtadkan kaum muslimin yang berada di daerah yang tekena bencana maupun warga miskin yang secara ekonomi lemah, dan tujuan mereka agar orang Islam yang di ajak mau mengikuti nya dengan berat hati terhadap bantuan yang mereka terima.

Harapan gerakan dakwah dilakukan untuk menyelamatkan kaum muslimin yang telah menerima pengaruh terhadap lingkungan yang memprihatikan dengan kondisi lemahnya perekonomian di salah satu daerah kristenisasi yang telah lama di jadikan sasaran pada mereka dengan pendekatan yang sangat halus sekali. Diantara gerakan mereka untuk mendoktrin anak-anak kecil yang mulanya tidak paham, dari situ kemudian di ajak secara peralahan dengan halus sekali untuk ikut serta pada kegiatan di gereja yang dilakukan mereka.

Masjid biasanya hanya melakukan dakwah pada internal saja, padahal di eksternal masjid yang di anggap sebagai pusat kegiatan keislaman perlu adanya bakti sosial bagi masyarakat membutuhkan uluran tangan dari saudara muslim 
mereka, agar iman mereka yang terkikis oleh godaan duniawi yang menguntungkan mereka dan melemahkan ummat Islam itu sendiri secara agar mereka bisa leluasa bergerak kedepannya.

Hubungan yang dekat dengan gerakan dakwah berbasis hobi, karena masjid adalah bagian yang tidak bisa dipisahkan dari kehidupan spritual, sosial dan kultural umat Islam. Rasulullah sallallaahu 'alaaibi wassallam menjadikan masjid sebagai tempat untuk melaksanakan pemerintah Allah untuk senantiasa menyembahnya dengan aktivitas ibadah yang dilakukan hamba kepada robnya.

Dewasa ini keberadaan masjid semakin mengalami penyempitan peran dan fungsi, dari pusat pelayanan umat menjadi sekedar sarana ibadah pelengkap di berbagai tempat.

Masjid Nurul Islam Kajiduan dan komunitas bikers muslim dalam membendung kristenisasi yang berlangsung pada daerah kristenisasi di lamongan. Gerakan dakwah masjid berbasis hobi seperti ini sudah berjalan beberapa tahun terakhir untuk mengembangkan dakwah secara meluas.

Masjid Nurul Islam Kalijudan Surabaya juga beda dengan masjid lain dengan perkembangannya yang berperan sebagai masjid yang memiliki gerakan dakwah berbasis komunitas. Hal ini yang membuat kami tertarik untuk meneliti lebih jauh untuk meneliti program manajemen yang diterapkan masjid dan gerakan dakwah yang diterapkan oleh Komunitas Bikers Muslim.

Dalam penelitian ini metode yang diambil peneliti adalah metode kualitatif. penelitian kualitatif adalah penelitian yang dilakukan dalam memahami sebuah fenomena yang dialami oleh subjek penelitian seperti tindakan, persepsi, prilaku secara holistik, dengan cara deskripsi membentuk kata-kata dan bahasa dalam konteks khusus, alamiyah, memanfaatkan metode ilmiah. (Meleong,2014:6)

Peneliti menggunakan jenis pendekatan kualitatif deskriptif, karena pada penelitian ini peneliti ingin mengetahui seperti apa sinergitas gerakan dakwah masjid nurul Islam kalijudan dan komunitas bikers muslim dalam membendung kristenisasi di daerah lamongan.

Teknik pengumpulan datanya menggunakan observasi, wawancara, dokumentasi, dan Teknik validitas datanya menggunakan triangulasi data, dan Teknik analisis datanya menggunakan analisis deskriftif kualitatif.

Teknik validasi data yang digunakan adalah triangulasi data dan teknik analisis datanya adalah menggunakan data collection (pengumpulan data), data reduction (reduksi data), data display (penyajian data), dan conclusion drawing/verification (kesimpulan dan verifikasi).

Dalam penelitian ini metode yang diambil peneliti adalah metode kualitatif. penelitian kualitatif adalah penelitian yang dilakukan dalam memahami sebuah fenomena yang dialami oleh subjek penelitian seperti tindakan, persepsi, prilaku 
secara holistik, dengan cara deskripsi membentuk kata-kata dan bahasa dalam konteks khusus, alamiyah, memanfaatkan metode ilmiah. (Meleong,2014:6)

Peneliti menggunakan jenis pendekatan kualitatif deskriptif, karena pada penelitian ini peneliti ingin mengetahui seperti apa sinergitas gerakan dakwah masjid nurul Islam kalijudan dan komunitas bikers muslim dalam membendung kristenisasi di daerah lamongan.

Teknik pengumpulan datanya menggunakan observasi, wawancara, dokumentasi, dan Teknik validitas datanya menggunakan triangulasi data, dan Teknik analisis datanya menggunakan analisis deskriftif kualitatif.

Teknik validasi data yang digunakan adalah triangulasi data dan teknik analisis datanya adalah menggunakan data collection (pengumpulan data), data reduction (reduksi data), data display (penyajian data), dan conclusion drawing/verification (kesimpulan dan verifikasi).

\section{LANDASAN TEORITIS}

Masjid bagi umat Islam memiliki makna yang sangat besar dalam kehidupan, baik makna fisik maupun makna spiritual. Kata masjid itu sendiri berasal dari kata - سجد yang mempunyai arti tempat sujud. Masjid setidaknya memiliki tiga fungsi. Pertama, masjid berfungsi sebagai pusat ibadah, baik ibadah mahdhah maupun ibadah sosial, termasuk diantaranya melayani kesehatan kepada masyarakat. Kedua, masjid berfungsi sebagai pusat pengembangan masyarakat. Ketiga, masjid berfungsi juga sebagai pusat pembinaan dan per satuan umat. (Al faruk,2010:255)

Di zaman Rasulullah shollallahu 'alaihi wassalam. masjid dijadikan sebagai central utama seluruh aktivitas keummatan. Baik untuk kegiatan pendidikan yakni tempat pembinaan dan pembentukan karakter sahabat maupun aspek-aspek lainnya termasuk politik, strategi perang hingga pada bidang ekonomi, hukum, sosial dan budaya. Singkatnya, masjid difungsikan selain sebagai pusat kegiatan ibadah spritual juga dijadikan tempat untuk melaksanakan ibadah muamalah yang bersifat sosial. Seiring dengan perkembangan zaman yang saat ini, sebagian besar masyarakat Indonesia beranggapan bahwa masjid hanya sebatas tempat ibadah saja. Seperti sholat berjama'ah, pengajian, dll. Padahal, fungsi masjid sangatlah besar pengaruhnya sebagai central utama bagi seluruh umat Islam. (Suherman, 2012:25-26)

Masjid sudah harus dilengkapi fasilitas dan sistem untuk melayani masyarakat. Karena jika masjid memiliki fasilitas dan sistem yang mampu melayani masyarakat, maka umat Islam berpotensi untuk bangkit dari keterpurukan dan menjadi umat yang maju di segala sektor bidang. Termasuk skala prioritas bagi 
ummat Islam adalah membendung kristenisasi untuk mempertahankan iman kaum muslimin yang dijadikan sasaran pada mereka yang berusaha untuk melemahkan islam dari berbagai aspek kehidupan.

\section{HASIL DAN PEMBAHASAN}

Dalam bagian ini akan dipaparkan hasil penelitian yang didapat dari data di lapangan dan pembahasan yang dikaji secara mendalam. Dan berisi analisis datadata dari lapangan.

Sejarah sinergitas masjid nurul Islam kalijudan dan komunitas bikers muslim Masjid dan komunitas awal berdiri pada tahun 2017 dan sudah berjalan 3 tahun. Awal berdiri sinergi ini di awali dengan aktifnya ustadz fuadi mengisi kajian di masjid nurul Islam kalijudan, dan ketika beliau di tunjuk menjadi ketua komunitas bikers muslim surabaya, beliau dan anggota komunitas hanya membuat kegiatan kumpul di warkop-warkop dan akhirnya pak hanafi selaku ketua takmir menawarkan kepada ustadz fuadi untuk menjadikan masjid Nurul Islam Kalijudan sebagai basecamp komunitas bikers muslim untuk melakukan kegiatan kopdar rutin serta harapan pak hanafi agar masjid semakin makmur dengan keberadaan anggota dari komunitas bikers muslim.

Latar belakang terjalinya kerjasama masjid dan komunitas ini pada dasarnya untuk membentuk suatu komunitas yang lebih dari sekedar masjid biasa untuk memperluas jangkauan dakwahnya pada eksternal masjid dengan menjalin sinergi bersama komunitas bikers muslim. Titik fokusnya kemudian tertujuh pada satu daerah kristenisasi di lamongan dalam rangka merangkul,membantu, dan membersamai saudara muslim kita disana yang membutuhkan perhatian khusus dari muslim yang lain ditengah kondisi masyarakat nya yang miskin, terjadi kekeringan, dan pergerakan kristenisasi yang melemahkan iman mereka.

Berdasarkan hasil informasi dari ketua takmir masjid nurul Islam kalijudan diketahui bahwa bekerjasama dengan komunitas bikers muslim diawali dengan untuk mencari tempat yang tepat untuk dikunjungi, dibantu, dan sekaligus temapt untuk berdakwah berdasarkan hasil survey dapat diketahui bahwa daerah tersebut memerlukan bantuan. sehingga dilakukan bakti social demi membendung gerakan kristenisasi di daerah itu. Kristenisasi itu muncul karena dari segi ekonomi kurang, sehingga mereka dengan mudah tertarik dengan ajakan-ajakan orang-orang kristen dilajutkan dengan beberapa kegiatan yang diikuti. Selain itu, strategi yang dilakukan adalah dengan cara pacarana, menikah kemudian pindah agama.

Hal itulah yang menjadi alas an adanya Kerjasama secara rutin dilakukan antara komunitas bikers muslim, pengurus masjid, pengusaha dan para ustadz.

.Struktur takmir masjid nurul Islam kalijudan adalah sebagai berikut : 
Ketua Takmir : H. Hanafi

Bendahara : Suryanto

Sekertaris :Drs. M. Ridwan

Wakil Sekertaris : R. Ananda

Koordinator Remas : E.K. Rais Al Hakim

Kanbid. Sarpras \& Keamanan : Punto Dewo

Sie Pembangunan : H. Suwandi dan Suhadi

Sie Perawatan \& Kebersihan : Nurmadi dan Ridwan

Sie Keamanan : Agus Rudiyanto dan Hermanto

Kabid Infokom \& Humas : DR. Anas

Sie Humas : M. Abadi dan Redjo A.M

Sie IT\& Pubdok : A. Yusdiwantoro

Kabid Sosial \& SIZ : H. Isnan Zulfan

Sie, Sosial : M. Nur Siswanto dan Sugianto

Sie SIZ : Kaiyan, h. Sijlarno, dan Doeng Mulyadi

Kabid PHBI dan Dakwah : Kuswandi dan M. Amiruddin

Sie Pemuda dan Diklat : Ahmad Tiono

Muslimah : Lilik Yuliana.

Sebagaimana diketahui bahwa Sinergi adalah membangun kepercayaan dalam organisasi. Dalam organisasi, kemampuan untuk membangun, menumbuhkan, menjaga dan mengembalikan semua kepercayaan para pemangku kepentingan maupun rekan kerja merupakan kunci sinergi.

Hasil penelitian kami pada sinergi dakwah masjid nurul Islam kalijudan dan komunitas bikers muslim, Hal ini memang sangat baik sekali. langkah yang di ambil oleh masjid untuk mengembangkan perannya dalam memperluas fungsi dakwah masjid pada masyarakat luas, walaupun hal yang dilakukan di daerah kristenisasi di lamongan memang relatif singkat.

Program kegiatan akan berlangsung secara berkala sesuai kesepakatan. Kemudian, apa saja yang bisa dilakukan pada sinergi dakwah berbasis hobi di daerah kristenisasi di lamongan. Apakah banyak hal yang bisa diselenggarakan untuk membendung kristenisasi pada sinergi dakwah ini :

penanaman aqidah yang kuat ke masyarakat untuk pentingnya kembali 
kepada agamanya, Islamnya, supaya mereka lebih dengan memperkuat lagi dengan menyibukkan diri hadir di masjid, mengikuti kajian-kajian yang diadakan oleh ustadz-ustadz setempat itu dan juga, tema-tema persoalan aqidah yang dirapakan itu bisa di dalami lagi oleh masyarakat, supaya mereka bisa akhirnya mereka tidak tergoda terhadap program-program yang terindikasi pemurtatan tadi. Selain itu, beberapa kegiatan yang lain diantaranya adalah kegiatan bakti sosial dengan bagi sembako pada masyarakat. Kemudian pembagian sembako pada para imam masjid dan para da'I yang disana. Kemudian juga melakukan kegiatan bersih-bersih masjid, memberikan Al-Qur'an dan buku pada masjid, setelah itu, kita adakan acara khusus anak-anak berupa permainana dan pembagian hadiah untuk mereka. Kemudian kita undang masyarakat dalam satu sesi acara yang melibatkan pihak Babinsa (Bintara pembina desa) setempat.

Sinergi dakwah ini dilakukan dalam rangka memberikan perhatian khusus kepada saudara muslim kita disana dalam mengokohkan aqidahnya agar tidak mudah diajak untuk berpindah agama dan tetep teguh dengan keislamannya.

Adapun beberapa kendala yang ada diantaranya: kami sadar bahwa ini program besar, butuh jangka panjang, sementara kita cuman hadir sesaat dan ibaratnya sekedar mencelup itu aja, memberikan warna yang tidak terlalu lama. Tapi harapan kami sebenarnya memang harus ada intensitas atau kontinyu berkelanjutan oleh program ini. Sudah dilakukan oleh beberapa ormas-ormas yang mereka mengirim da'i-da’i mereka. Dan kami sadar bahwa bukan kapasitas kami, karna kami cuman sekedar komunitas saja. Tapi kita tetap support karna dakwah itu. Kemudian kendala berikutnya dari sisi lemahnya SDM kami, ya. Artinya kan, SDM kami memang belum terbiasa dengan menangani medan-mdan seperti itu. Apalagi medannya lumayan berat, tidak terbiasa untuk kendala yang di luar atau di eksternal kami. Kondisi alam yang memang lagi kering, kekeringan air, terbatas, kemudian jalanan yang terjal bebatuan. Nah ini, karna tidak semua motor support untuk kesana. Kemudian, kendala berikutnya, sebenarnya kami ingin kehadiran para imam, serta ustadz-ustadznya, tapi Qodorullah, pas ustadz-ustadznya dan para imamnya lagi, pulang kampung. Iya, sehingga kami belum mampu. Kemudian jenis bantuan yang kami berikan, masih belum banyak. Ya. Harapannnnya memang, ,kita ingin tangani semuanya, tapi itu tadi, melihat kemampuan, jadi kita harus mengukur diri untuk itu.

\section{P}




\section{ENUTUP}

Dengan semua usaha yang telah dilakukan untuk memberikan bantuan sosial dan perhatian kepada saudara muslim kita yang tertindas dan terancam dalam situasi yang tidak baik di daerah kristenisasi dilamongan, kehadiran komunitas bikers muslim dengan sinergi bersama masjd nurul Islam kalijudan sudah sangat membantu dalam membendung aqidah dan mempertahankan pendiriannya dalam berislam secara penuh untuk mempertahankan agama yang haq.

Adapun saran untuk kegiatan ini, memang perlu adanya SDM yang berkompoten dari pihak manapun, juga untuk membangun sinergi yang lebih besar untuk selalu mengawal daerah-daerah kristenisasi dalam rangka upaya untuk menyelamatkan aqidah dan keimanan saudara muslim kita yang lain.

\section{DAFTAR PUSTAKA}

Ester, L. (2014). Perjanjian Kemitraan Sebagai Pola Kerjasama Penerapan Corparan Sosial Responsibility. Surabaya: Universitas Airlangga.

Hafsah, M. J. (1999). Kemitraan Usaha. Pustaka Sinar Harapan. Jakarta.

Indraningrum, P. (2015). Pengembangan Program Sanggar Kegiatan Belajar (SKB) Gunung Kidul Melalui Model Kemitraan. Yogyakarta: Universitas Negri Yogyakarta.

Indrawan, R, \& Yaniawati,P. (2016). Metodologi Penelitian Kuantitatif ,Kualitatif, dan Campuran, Untuk Manajemen, Pembangunan, dan Pendidikan. Bandung : Refika Aditama.

Isma'il, A.Q, \& Ahmad, M A. (2007). Pelayanan dan Tamu di Rumah Allah. Jawa Timur: Pustaka Sidogiri.

KBBI (Kamus Besar Bahasa Inodnesia)

Meleong, J. L. (2016). Metode Penelitian Kualitatif. Bandung: Rosda karya.

Mukhtar. (2013). Metode Praktis Penelitian Deskriptif kualitatif. Jakarta: Press Group.

Raco. (2010). Metode Penelitian Kualitatif. Jakarta: Grasindo.

Rohidi, T. R. (1992). Analisis Data Kualitatif. Jakarta: UI Press.

Rukmana, N. (2006). Stategic Patnering For Education Management Model Manajemen Pendidikan Berbasis Kemitraan. Bandung: Alfabeta.

Seherman, E. (2012). Manajemen Masjid; kiat sukeses meningkatkan kualitas SDM melalui optimalisasi kegiatan umat berbasis pendidikan berkualitas unggul. Bandung: ALFABETA.

Sugiono. (2016). Metode Penelitian Pendidikan, Pendekatan Kuantitatif Kualitatif dan R\&D. Bandung: Alfabeta.

Sugiyono. (2009). Memahami Penelitian Kualitatif. Bandung: Alfabeta.

Sulistiyani, A.T. (2004). Kemitraan Dan Model-Model Pemberdayaan. Yogyakarta: Gaya Media. 
Dakwah Komunitas (Sinergitas Masjid Nurul Islam Kalijudan Dan Komunitas Bikers Muslim Dalam Membendung Kristenisasi)

Tim Fokkus Babinrohis Pusat \& Icmi Orsat Cempaka Putih \&Yayasan Kado Anak Muslim, Pedoman Manjemen Dakwah.

Utami, F.N. (2013). Peran Public Relations Pada Organisasi Non Profit Program Konservasi Kelautan WWF-Indonesia. Bogor: Institut Pertanian Bogor. 
A.Ahmad 